\title{
Groin Pain In Pregnancy - Is It Omnious?
}

\author{
Chonkar Sonali*1 and Koh Qiao Ying Stephanie ${ }^{2}$ \\ ${ }^{1}$ Staff Physician, KK Women's and Children's Hospital, Singapore \\ ${ }^{2}$ Medical student, NUS Yong Loo Lin School of Medicine, Singapore
}

Received: April 07, 2018; Published: April 23, 2018

*Corresponding author: Chonkar Sonali, Staff Physician, KK Women's and Children's Hospital, Singapore, Tel: 6581890120; Email: Sonali.chonkar@kkh.com.sg

\section{Introduction}

Pregnancy has been known to put women in a hypercoagulable state. This has been postulated to be the body's physiological response to the maternal's susceptibility to bleeding risks during the antenatal and postnatal period [1-3]. Thus, pregnant women are four to five times more likely to develop venous thromboembolism (VTE) [4], putting the incidence to about 0.71 per 1000 pregnancies [4]. VTE is known to affect pregnant women from $1^{\text {st }}$ trimester up to post partum [5] with the risk of VTE being higher as the woman progresses later in her pregnancy [6]. VTE in pregnancy is also more known to affect the left lower limb than the right, with a weighted event rate of $77.2 \%$ for left sided or bilateral lower limb deep vein thrombosis and $21.5 \%$ for right sided deep vein thrombosis [5].

Although maternal hemorrhage is the leading cause of mortality in developing countries, VTE, in particular pulmonary embolism is the leading cause of maternal mortality in developed countries [7]. According to a US study done from 1999 to 2009, out of 746 maternal deaths, 61 (8.1\%) was due to VTE-related disease [8]. This further augments the importance of developing strategies to reduce the incidence of venous thromboembolism in pregnant women. Moreover, the use of assisted reproductive technology to achieve conception has been on the rise [9]. Along with its advent, in vitro fertilization (IVF) has been reported to double to risk of VTE in pregnancy, despite the absolute risk being presumably low [10]. The following case we report is about an IVF patient in her $1^{\text {st }}$ trimester with an unusual presentation of left sided VTE.

\section{Case Report}

A 34 year old G1P0 Chinese female, married, presented to the KK Women's and Children's Hospital's 24 hour O\&G emergency clinic with left groin pain of 6 days duration. She had $12+1$ weeks of amenorrhea and was pregnant at that time. She conceived through in-vitro fertilization, her last menstrual period was $17^{\text {th }}$ March 2017 and her estimated delivery date was $18^{\text {th }}$ December 2017. Her pregnancy was otherwise normal with no known medical disorders. She denied having any past surgeries and no significant family history. She was on Dydrogesterone and folic acid supplements. Her left groin pain started 6 days ago and radiated to the medial aspect of her thigh. This pain had been increasing in intensity over those couple of days and was worse on straining and walking. Her pain score at the 24 hour $0 \&$ G clinic was $8 / 10$. She did not take any pain relieving medications for the pain.

There was no abdominal pain, per vaginal bleeding or discharge. The pain was also not associated with any fever. There was no prior trauma or strenuous exercises. The pain was unbearable until she was no longer able to ambulate, which led to her visit at the 24 hour $0 \&$ G clinic. At the 24 hour $0 \& G$ clinic, she had a normal pulse, normal blood pressure and was afebrile. On examination, she looked like she was in distress. There was no conjunctival pallor and her sclera was anicteric. There left iliac fossa tenderness but no rebound tenderness or guarding. Her heart sounds were normal and her lungs were clear. Her lab results (full blood count and renal panal) were normal. On transvaginal ultrasound, a viable intrauterine pregnancy was seen with the crown rump length of the fetus of $5.5 \mathrm{~cm}$ which was appropriate for dates. There was fetal cardiac activity with fetal heart rate of 165 beats per minute.

Her left ovary was normal with a size of $4.2 \mathrm{~cm}$ by $1.9 \mathrm{~cm}$ and Doppler colour flow analysis of the ovarian and uterine arteries were normal. There was no suspicious adnexal masses or free fluid in the pelvis. She was subsequently discharged with paracetamol and a follow up appointment. Subsequently, she returned for follow up on $29^{\text {th }}$ June 2017 with left lower limb swelling that started 7 days before. There was no contraction pain, per vaginal bleeding or discharge, and fetal movements were good. She did not have any shortness of breath, cough or palpitations, and did not have any changes in urinary and bowel habits. Her vitals were normal but on examination, there was mild pitting edema on her left lower limb. This was associated with some erythema but there was no pain or fever.

Her pedal pulse, posterior tibial and popliteal pulses were present and strong bilaterally. Her abdomen was soft and non- 
tender, her heart sounds were normal, and her lungs were clear. With a provisional diagnosis of left lower limb deep vein thrombosis, a Doppler ultrasound of the lower limbs and pelvis was done, which revealed decreased colour flow and compressibility in the left distal external iliac, common femoral, superficial femoral and popliteal veins. This confirmed our diagnosis of left lower limb deep vein thrombosis. The patient was started on therapeutic clexane $60 \mathrm{mg}$ twice daily, which was to be taken till delivery. A repeat Doppler ultrasound was done about a month later with a follow up to the hematologist which showed reduction in thrombosis.

\section{Discussion}

Pregnant women are more at increased risk of VTE [1]. Previous studies have suggested that venous thromboembolisms are more common in pregnant women in their third trimester than in the $1^{\text {st }}$ or $2^{\text {nd }}$ trimester [6]. The risk of VTE in pregnant women in their third trimester is 6.1 times more than in women who are not pregnant, which is substantially higher compared to pregnant women in their $1^{\text {st }}\left(1.6\right.$ times) and $2^{\text {nd }}$ (2.1 times) trimester[11]. Thus, there VTE in pregnant women with left iliac pain in their 1st trimester are more likely to be missed. However, VTE is also known to occur in pregnant patients in their $1^{\text {st }}$ trimester. This is postulated to be due to increased thrombin production during pregnancy, which is known to increase in production from as early as at 5 weeks gestation, and it increases to 8 weeks gestation [12]. According to the Royal College of Obstetricians and Gynaecologists (RCOG) guidelines [13], there are several risk factors currently associated with increased risk of VTE in pregnancy, which can be divided into major, moderate and minor risk factors: (Table 1).

Table 1.

\begin{tabular}{|c|c|c|}
\hline Major & Moderate & Minor \\
\hline $\begin{array}{c}\text { Any Previous History } \\
\text { of VTE Except a Single } \\
\text { Event Related to Major } \\
\text { Surgery }\end{array}$ & $\begin{array}{c}\text { Hospital admission } \\
\text { Single previous VTE related to major surgery } \\
\text { High risk thrombophilia without history of VTE } \\
\text { Medical comorbidities (eg. cancer, heart failure, active SLE, } \\
\text { IBD or inflammatory polyarthropathy, nephrotic syndrome, } \\
\text { type I DM with nephropathy, sickle cell disease, current } \\
\text { intravenous drug user } \\
\text { Any surgical procedure (eg. appendicectomy) } \\
\text { OHSS (1 } 1^{\text {st }} \text { trimester only) }\end{array}$ & $\begin{array}{c}\text { Obesity }(\text { BMI }>30 \mathrm{~kg} / \mathrm{m} 2) \\
\text { Age }>35 \\
\text { Parity } \otimes 3 \\
\text { Smoker } \\
\text { Gross varicose veins } \\
\text { Current pre-eclampsia } \\
\text { Immobility, eg. paraplegia, PGP } \\
\text { Family history of unprovoked or estrogen-provoked VTE in } \\
1^{\text {st }} \text { degree relative } \\
\text { Low-risk thrombophilia } \\
\text { Multiple pregnancy } \\
\text { IVF/Assisted Reproductive Technology (ART) }\end{array}$ \\
\hline
\end{tabular}

In the case presented above, the patient was considered low risk as her only known risk factor was having undergone IVF treatment, which in itself, is a minor risk factor. There have been studies done that have revealed IVF as an important risk factor for VTE. In fact, one study in Denmark showed that VTE in pregnant women who had underwent IVF treatment had an incidence rate ratio of 3.0 compared to reference pregnancies [14]. In another Swedish systematic review, IVF was shown to double the antepartum risk of VTE [15]. In particular, another Swedish study revealed that the risk of VTE in the $1^{\text {st }}$ trimester of IVF conceived patients was 4 times higher and risk of pulmonary embolism (PE) in the same group of patients was 7 times higher [16]. It is thus prudent to remain vigilant when taking care of pregnant women who have gone through IVF in their $1^{\text {st }}$ trimester.

\section{References}

1. Gherman RB, Goodwin TM, Leung B, Byrne JD, Hethumumi R, et al (1999) Incidence, clinical characteristics, and timing of objectively diagnosed venous thromboembolism during pregnancy, Obstet. Gynecol 94: $730-734$.

2. James AH, Tapson VF, Goldhaber SZ (2005) Thrombosis during pregnancy and the postpartum period. Am J Obstet Gynecol 193(1): 216-219.
3. Pomp ER, Lenselink AM, Rosendaal FR, Doggen CJ (2008) Pregnancy, the postpartum period and prothrombotic defects: risk of venous thrombosis in the MEGA study. J Thromb Haemost 6(4): 632-637.

4. McColl MD, Ramsay JE, Tait RC, Walker ID, McCall F, et al. (1997) Risk factors for pregnancy-associated venous thromboembolism. Thromb Haemost 78(4): 1183-1188.

5. Ray JG, Chan WS (1999) Deep vein thrombosis during pregnancy and the puerperium: a meta-analysis of the period of risk and the leg of presentation. Obstet Gynecol Surv 54(4): 265-271.

6. Jacobsen AF, Skjeldestad FE, Sandset PM (2008) Incidence and risk patterns of venous thromboembolism in pregnancy and puerperium-a register-based case-control study. Am J Obstet Gynecol 198(2): e231-e237.

7. Cantwell R, Clutton Brock T, Cooper G, Dawson A, Drife J, et al. (2011) Saving Mothers' Lives: Reviewing maternal deaths to make motherhood safer: 2006-2008. Br J Obetet Gynaecol 118: 1-203.

8. Abbasi N, Balayla J, Laporta DP, Kezouh A, Abenhaim HA (2014) Trends, risk factors and mortality among women with venous thromboembolism during labour and delivery: a population-based study of 8 million births. Arch Gynecol Obstet 289(2): 275-284.

9. (2000) International Committee for Monitoring Assisted Reproductive Technology, Adamson GD, de Mouzon J, Lancaster P, Nygren KG, et al. (2006) World collaborative report on in vitro fertilization, 2000. Fertil Steril 85(6): 1586-1622. 
10. Rova K, Passmark H, Lindqvist PG (2012) Venous thromboembolism in relation to in vitro fertilization: an approach to determining the incidence and increase in risk in successful cycles. Fertil Steril 97(1): 95-100.

11. Alyshah Abdul Sultan, Joe West, Laila Tata J, Kate Fleming M, Catherine Nelson-Piercy, et al. (2016) Risk of first venous thromboembolism in and around pregnancy: a population-based cohort study. British Journal of Haematology 156: 366-373.

12. CN Bagot, E Leishmana, Onyiaodike CC, Jordan F, Freeman DJ (2017) Normal pregnancy is associated with an increase in thrombin generation from the very early stages of the first trimester. Thrombosis Research 157: 49-54.

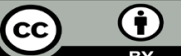

This work is licensed under Creative Commons Attribution 4.0 License

Submission Link: https://biomedres.us/submit-manuscript.php
13. (2015) Reducing the Risk of Venous Thromboembolism during Pregnancy and the Puerperium. Royal College of Obstetricians and Gynaecologists, RCOG Green-top Guideline No. 37a, England.

14. Hansen AT, Kesmodel US, Juul S, Hvas AM (2014) Increased venous thrombosis incidence in pregnancies after in vitro fertilization. Human Reproduction 29(3): 611-617.

15. Sennstr€om M, Rova K, Hellgren M, Hjertberg R, Nord E, et al. (2017) Thromboembolism and in vitro fertilization - a systematic review. Acta Obstet Gynecol Scand 96(9): 1045-1052.

16. Henriksson P, Westerlund E, Wallén H, Brandt L, Hovatta O (2013) Incidence of pulmonary and venous thromboembolism in pregnancies after in vitro fertilisation: cross sectional study. BMJ 346: e8632.

Assets of Publishing with us
RIOMEDICAL
RESERCHES

